\title{
Visualizing Frailty: Exploring Radiographical Measures of Frailty in Trauma Patients
}

\author{
Omolola Fakunle a,*, Meet Patel a, Victoria G. Kravets a, Adam Singer b, Robert Hernandez-Irizarry c, \\ Mara L. Schenker ${ }^{c}$ \\ ${ }^{a}$ Department of Orthopedic Surgery, Emory University School of Medicine, Atlanta, GA, USA \\ ${ }^{b}$ Department of Radiology and Imaging Sciences, Emory University School of Medicine, Atlanta, GA, USA \\ ${ }^{c}$ Division of Orthopedic Trauma, Emory University School of Medicine, Atlanta, GA, USA
}

\section{Article history:}

Recevied: May 12, 2021

Revised: August 26, 2021

Accepted: August 26, 2021

\begin{abstract}
Purpose: This study assessed the relationship of core muscle sarcopenia, myosteatosis, and L1 attenuation to the 5-factor modified frailty index ( $\mathrm{mFI}-5$ ), discharge disposition, and post-admission complications in orthopedic and general trauma patients. It was hypothesized that reduced sarcopenia, L1 attenuation, and increased myosteatosis is associated with higher mFI-5 scores ( $\geq 0.3)$, discharge into care, and increased post-admission complications.
\end{abstract}

Methods: This prospective cohort study was performed at a Level 1 trauma center. Patients were surveyed and metrics of the mFI- 5 were used. Frail was categorized as a mFI- 5 score $\geq 0.3$. Recent abdominal computed tomography (CT) scans were used to extract radiographical information of total psoas cross-sectional area, psoas myosteatosis, and L1 vertebrae attenuation.

Results: There were 140 patients who consented to the study, of which 83 had available abdomen and pelvis CT scans. The mean age was $43.19( \pm 17.36)$, and $65 \%$ were male $(n=52)$. When comparing the frail $(16 \%, n=13)$ and not frail $(84 \%, n=70)$ patients, there was a significant difference in mean psoas myosteatosis $(p<0.0001)$ and the attenuation of the L1 vertebrae $(p<0.001)$. On multivariate analysis when accounting for age, myosteatosis of the psoas muscles was predictive of an mFI-5 score $\geq 0.3$.

Conclusion: The findings suggest that myosteatosis and L1 attenuation are associated with frailty indices (mFI-5) after traumatic injury. Future studies are needed to prospectively assess the validity of both radiographical and index-based markers of frailty in predicting post-traumatic complications, mortality, and hospital utilization.

Keywords: abdomen, frailty, injury, radiology, sarcopenia, trauma

\section{ORCID}

Mara L. Schenker

https://orcid.org/ 0000-0001-8630-079X

\section{Introduction}

Frailty is a syndrome of decreased physiological reserve characterized by marked vulnerability to morbidity and mortality [1-3]. Until recently, frailty had been seen as an age-related decline in health, but recent studies have shown non-geriatric trauma can also be determined by the modified frailty indices $(\mathrm{mFI})[4]$. A variable number of frailty indices have been used in trauma and non-trauma populations ( 5 indices [5-10], 11 indices [10-12], and 15 indices [13]), and all have been shown to predict adverse outcomes including in-hospital complications, mortality, and increased hospital utilization. A limitation of commonly used frailty assessments is that they require the extrapolation of information from a conscious patient or identified patient chart which may prove unfeasible in a trauma setting [14]. In trauma, frailty often goes unrecognized until later in the course of treatment thus, limiting the capacity of medical staff to provide early coordination of care for frailty-specific factors [15]. Therefore, a fast and straightforward tool to assess frailty which is 
independent of patient mental status, would be clinically useful.

Radiographical markers of frailty, including psoas atrophy [16-20] and L1 attenuation [21,22] have previously been described. Psoas atrophy is characterized by sarcopenia (or decreased muscle mass) [23-25] and myosteatosis (fatty infiltration of the muscle) [26]. Sarcopenia, measured as crosssectional surface area $\left(\mathrm{cm}^{2}\right)$ of the core psoas muscle, has been reported to predict complications in surgical transplant and cancer patient populations [27-29]. Myosteatosis, a radiodensity measure of heterogenous muscle architecture, measured in Hounsfield units (HU), has been reported to predict morbidity and mortality in pancreatic [30], metastatic [31], and liver [32] cancer patients. L1 attenuation, the radiodensity of the 1st lumbar vertebra, has been associated with aging and osteoporosis [22], and has been reported to have factors related to frailty [33-35].

The purpose of this prospective study was to answer 2 questions: (1) Is there a relationship between radiographical markers of frailty (sarcopenia, myosteatosis, and L1 attenuation) and the widely used frailty indices in trauma patients; and (2) Are radiographical markers of frailty associated with in-hospital complications, and hospital utilization by trauma patients. It was hypothesized that frailty indices were associated with radiographical markers of frailty, in-hospital complications, and adverse hospital utilization. We aim to lay the groundwork for crafting a radiographical tool for risk stratification, triage, and coordination of care for trauma patients.

\section{Materials and Methods}

\section{Study design}

Following approval from the institutional review board (no.: IRB00086957), this prospective cohort study recruited patients between June and July 2019 at a Level 1 trauma center. All orthopedic, and general trauma patients were screened for participation, and those who participated in the study gave informed consent. The inclusion criteria were: $>18$ years of age, hospitalized due to traumatic injury to the chest/ abdomen/pelvis (CAP), received a computed tomography (CT) scan upon admission, and were not pregnancy or incarcerated.

\section{Frailty indices}

The trauma-specific 5-factor modified frailty index (mFI-15) score was determined directly using a patient questionnaire (when patient mental status allowed) [13]. The mFI-5 score was calculated from co-morbidity data (diabetes mellitus, hypertension, chronic obstructive pulmonary disease, congestive heart failure, and functionally dependent health

status) collected from the institute trauma registry. A frailty index score greater than or equal to 0.3 was designated as frail [11].

\section{Radiographical markers of frailty}

Under the guidance of a fellowship-trained musculoskeletal radiologist, radiographical measurements for sarcopenia, myosteatosis, and L1 attention were measured on CT CAP scans. Measurements were obtained by analysts who were blinded to the frailty score of the patient.

Sarcopenia was defined as the total psoas in a cross-sectional area $\left(\mathrm{cm}^{2}\right)$ measured at the apex of the lumbar lordotic curvature (Figure 1). The apex of the lordotic curvature was consistent with the $3^{\text {rd }}$ or $4^{\text {th }}$ lumbar vertebral levels (L3, L4) in all patients. The apex at L3 or L4 was first identified on the sagittal view. Subsequent cross-sectional measurements were taken around the 2 core psoas muscles in the transverse view, with the free hand region of interest tool, at the level where spinal processes of the target vertebra could be visualized. Smaller psoas cross-sectional areas are consistent with decreased muscle sizes. Myosteatosis was measured as radiodensity of the psoas in Hounsfield units (HU), also measured at the same level as the psoas cross-sectional area (Figure 1). A lower HU indicated fatty infiltration. Total psoas cross-sectional area, average $\mathrm{HU}$, and standard deviation measurements were recorded for both psoas muscles.

For L1 attenuation, the controlled site of measurement was at the superior trabecular portion of the 1st lumbar (L1) vertebra (Figure 2). The L1 vertebra was first identified on the sagittal view and the center of the vertebra was identified in transverse view with the use of a scout line. This ensured the measurements were taken at the midline of the vertebra. HU measurements were then taken with an elliptical region of interest tool, at the trabecular portion which lies superior to the mid-cortical region (Figure 2). L1 attenuation was measured in HU where a lower HU indicated lower bone density. Average HU and standard deviations were recorded.

Patients with injury or prior surgery involving the vertebral

(A)

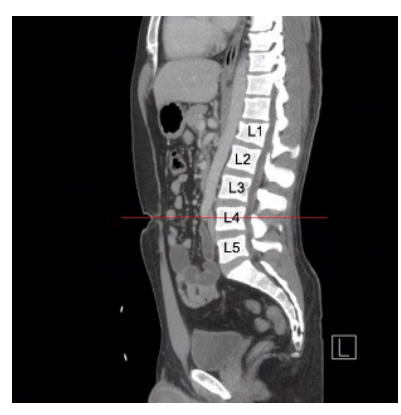

(B)

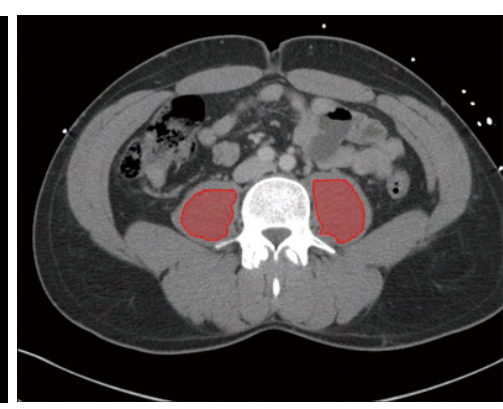

Figure 1. Psoas measurements. Transverse CT shows areas where myosteatotic and sarcopenic data were derived. 
(A)

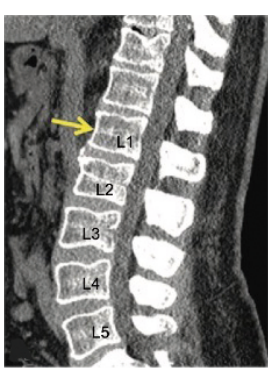

(B)

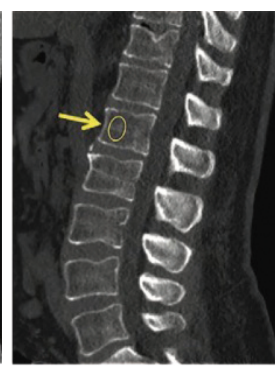

(C)

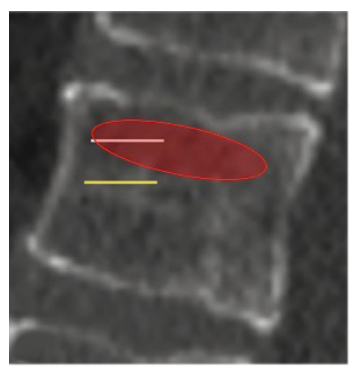

Figure 2. L1 attenuation. Sagittal CT shows derivation of the radiodensity of the $\mathrm{L} 1$ superior trabecular bone.

(A)

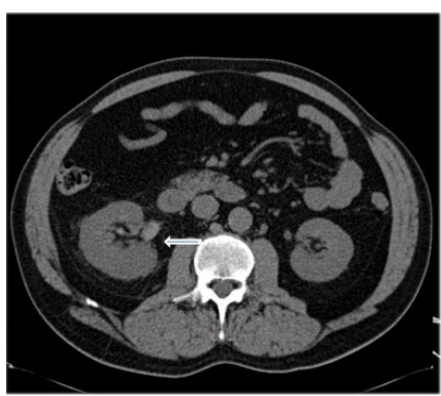

(B)

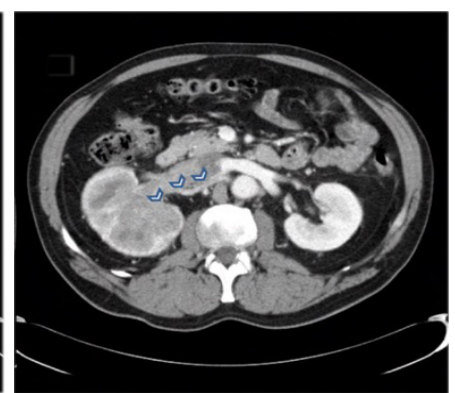

Figure 3. Importance of contrast. Radiodensity differences between CT without contrast (A and with contrast B).

bodies or psoas muscles between the 1 st and 5 th lumbar vertebra (L1-L5) were excluded from the study due to an inability to acquire consistent measurements.

The absence of contrast was recorded for all CAP CT scans. When intravenous contrast was administered, the phase (arterial vs. portal venous) of contrast was reported. A subset analysis including patients with only contrast CT scans was conducted in an effort to account for the radiodensity discrepancies between contrast and non-contrast CT scans (Figure 3).

The picture archiving and communication system software was the measurement program used to obtain all sarcopenia, myosteatosis, and L1 attenuation measurements.

\section{Disposition and complications}

Discharge data was collected (home verses care) from the institutional trauma registry (Tables 1 and 2). In-hospital complications were also taken from registry data, and included: acute kidney injury, acute lung injury, cardiac arrest, catheterrelated blood stream infection, decubitus ulcer, surgical site infection (deep, superficial, organ space), deep venous thrombosis, compartment syndrome, myocardial infarction, osteomyelitis, pneumonia, pulmonary embolism, sepsis, stroke, unplanned intubation, unplanned admission to the intensive care unit, unplanned return to the operating room, and urinary tract infection (Table 3).
Table 1. Relationship between radiographic and discharge disposition.

\begin{tabular}{|c|c|c|c|}
\hline & $\begin{array}{c}\text { Frail } \\
n=13(16 \%)\end{array}$ & $\begin{array}{c}\text { Not frail } \\
n=70(84 \%)\end{array}$ & $p$ \\
\hline Average HU & & & 0.5 \\
\hline Mean (SD) & $63.6(7.2)$ & $61.9(10.3)$ & \\
\hline $\begin{array}{l}\text { Mean (minimum, } \\
\text { maximum) }\end{array}$ & $63.3(42.8,81.7)$ & $60.5(42.5,87.6)$ & \\
\hline Average SA & & & 0.38 \\
\hline Mean (SD) & $26.1(7.6)$ & $30.4(22.1)$ & \\
\hline $\begin{array}{l}\text { Mean (minimum, } \\
\text { maximum) }\end{array}$ & $24.8(14.6,61)$ & $25(19.7,129.6)$ & \\
\hline Superior HU & & & 0.05 \\
\hline Mean (SD) & $225.8(71.6)$ & $190.7(70.6)$ & \\
\hline $\begin{array}{l}\text { Mean } \\
\text { (minimum, } \\
\text { maximum) }\end{array}$ & $\begin{array}{c}224.2(83.5 \\
392.1)\end{array}$ & $\begin{array}{c}179.3(80.9 \\
385.8)\end{array}$ & \\
\hline
\end{tabular}

HU = Hounsfield units; SA = surface area.

Table 2. Contrast CT-only analysis: relationship between radiographic and discharge disposition.

\begin{tabular}{|c|c|c|c|}
\hline & $\begin{array}{c}\quad \text { Frail } \\
n=13(16 \%)\end{array}$ & $\begin{array}{c}\text { Not frail } \\
n=70(84 \%)\end{array}$ & $p$ \\
\hline Average HU & & & 0.84 \\
\hline Mean (SD) & $63.9(7.2)$ & $64.4(9.2)$ & \\
\hline $\begin{array}{l}\text { Mean (minimum, } \\
\text { maximum) }\end{array}$ & $63.5(42.8,81.7)$ & $61.8(51.3,87.6)$ & \\
\hline Average SA & & & 0.83 \\
\hline Mean (SD) & $26.3(7.7)$ & $26(4.6)$ & \\
\hline $\begin{array}{l}\text { Mean (minimum, } \\
\text { maximum) }\end{array}$ & $25.2(14.6,61)$ & $24.2(19.7,38)$ & \\
\hline Superior HU & & & 0.26 \\
\hline Mean (SD) & $225.9(72.4)$ & $203.7(72.7)$ & \\
\hline $\begin{array}{l}\text { Mean (minimum, } \\
\text { maximum) }\end{array}$ & $\begin{array}{c}224.8(83.5 \\
392.1)\end{array}$ & $\begin{array}{c}208.8(80.9, \\
385.8)\end{array}$ & \\
\hline
\end{tabular}

$\mathrm{CT}$ = computed tomography; $\mathrm{HU}=$ Hounsfield units; $\mathrm{SA}=$ surface area.

\section{Statistical analysis}

Data was analyzed using $\mathrm{R}$ Version 3.6.1. The Student $\mathrm{t}$ test was used to assess frailty ( $\mathrm{mFI}$ score $\geq 0.3$ ), discharge disposition (home or care; Tables 1 and 2), and postadmission complications in relation to the 3 radiographical markers (Tables 4 and 5). Using multivariate analysis, whilst adjusting for age, each frailty index was represented as a binary "frail" ( $\mathrm{mFI}$ score $\geq 0.3$ ) vs "not frail" outcome, and correlated with respective measurements of sarcopenia, myosteatosis, and L1 attenuation. Spearman's rho coefficients were generated for multivariate analysis and were described as odds ratios. Receiver operator characteristics curves were 
used to determine the accuracy of the regression modeling. Significance was set as $p<0.05$.

Table 3. Post-Admission complications.

\begin{tabular}{l}
\hline Complication \\
\hline Acute kidney injury \\
Acute lung injury \\
Cardiac arrest modified frailty index/cardiopulmonary resuscitation \\
\hline Catheter related blood stream infection \\
\hline Decubitus ulcer \\
\hline Deep surgical site infection \\
\hline Drug/ethanol \\
Deep vein thrombosis/thrombophlebitis \\
Extremity compartment syndrome \\
Graft/prosthesis/flap failure \\
\hline Myocardial infarction \\
\hline Organ spacer surgical site infection \\
\hline Osteomyelitis \\
\hline Pneumonia \\
\hline Pulmonary embolism \\
\hline Sepsis \\
\hline Stroke/cerebrovascular accident \\
Superficial surgical site infection \\
\hline Unplanned intubation \\
\hline
\end{tabular}

Table 4. Relationship between radiographic markers and postadmission complications

\begin{tabular}{lccc} 
& Frail & Not frail & \\
& $n=13(16 \%)$ & $70(84 \%)$ & 0.76 \\
\hline Average HU & & & \\
Mean (SD) & $63(7.8)$ & $64.1(10.8)$ & \\
$\begin{array}{l}\text { Mean (minimum, } \\
\text { maximum) }\end{array}$ & $62.5(42.8,87.6)$ & $64.7(42.5,81.2)$ & \\
$\begin{array}{l}\text { Average SA } \\
\text { Mean (SD) }\end{array}$ & $27.3(13.9)$ & $27.9(7.4)$ & \\
$\begin{array}{l}\text { Mean (minimum, } \\
\text { maximum) }\end{array}$ & $24.5(14.6,129.6)$ & $27.4(17.8,44.1)$ & \\
$\begin{array}{l}\text { Superior HU } \\
\text { Mean (SD) }\end{array}$ & $210.8(71)$ & $252(75.2)$ & \\
$\begin{array}{l}\text { Mean (minimum, } \\
\text { maximum) }\end{array}$ & $210.8(80.9$, & $259.3(146.5$, & \\
\hline
\end{tabular}

$\mathrm{HU}=$ Hounsfield units; $\mathrm{SA}=$ surface area.
Table 5. Contrast CT-only analysis: relationship between radiographic markers and post-admission complications.

\begin{tabular}{|c|c|c|c|}
\hline & $\begin{array}{c}\text { Frail } \\
n=13(16 \%)\end{array}$ & $\begin{array}{c}\text { Not frail } \\
n=70(84 \%)\end{array}$ & $p$ \\
\hline Average HU & & & 0.3 \\
\hline Mean (SD) & $63.6(7.6)$ & $66.8(7.6)$ & \\
\hline $\begin{array}{l}\text { Mean (minimum, } \\
\text { maximum) }\end{array}$ & $63(42.8,87.6)$ & $66.7(57.8,81.2)$ & \\
\hline Average SA & & & 0.55 \\
\hline Mean (SD) & $26.1(6.9)$ & $27.9(8)$ & \\
\hline $\begin{array}{l}\text { Mean (minimum, } \\
\text { maximum) }\end{array}$ & $24.9(14.6,61)$ & $26.8(17.8,44.1)$ & \\
\hline Superior HU & & & 0.04 \\
\hline Mean (SD) & $214(70.6)$ & 273.7 (66.9) & \\
\hline $\begin{array}{l}\text { Mean(minimum, } \\
\text { maximum) }\end{array}$ & $\begin{array}{c}213.6(80.9, \\
392.1)\end{array}$ & $268.6(172.6,368.5)$ & \\
\hline
\end{tabular}

\section{Results}

The patients studied had an average age of $43.19( \pm 17.36)$ years, and there were $65 \%$ of patients who were male $(n=54)$, and $35 \%$ female ( $n=29$; Table 6$)$. Of the 83 patients included, 13 were identified as frail using the $\mathrm{mFI}-5$ ( $\mathrm{mFI}$ score $\geq 3.0$ ). Patients in the frailty group were significantly older $(p<0.001$; Table 7).

Table 6. Patient demographics.

\begin{tabular}{lcc}
\hline & $\begin{array}{c}\text { Full data set } \\
n=83\end{array}$ & $\begin{array}{c}\text { Contrast CT } \\
n=74\end{array}$ \\
\hline Age & $43.19( \pm 17.36)$ & $41.53( \pm 16.75)$ \\
mean y \pm SD) & & \\
Gender & $54(65 \%)$ & $25(34 \%)$ \\
Male & $29(35 \%)$ & $49(66 \%)$ \\
Female & & \\
Race & $48(58 \%)$ & $44(59 \%)$ \\
Black or African American & $31(37 \%)$ & $26(35 \%)$ \\
Other & $4(5 \%)$ & $4(5 \%)$ \\
Unknown & $15.57( \pm 8.58)$ & $15.49( \pm 8.69)$ \\
Mean ISS $( \pm$ SD) & $20.59( \pm 36.9)$ & $19.89( \pm 37.45)$ \\
Mean LOS $( \pm$ SD) & & \\
Discharge disposition & $57(69 \%)$ & $54(73 \%)$ \\
Home & $25(30 \%)$ & $19(26 \%)$ \\
Care & & \\
\hline
\end{tabular}

$\mathrm{CT}=$ computed tomography. 
Table 7. Patient demographics by frailty.

\begin{tabular}{lccc}
\hline $\begin{array}{l}\text { Demographics by } \\
\text { frailty }\end{array}$ & $\begin{array}{c}\text { Frail } \\
n=13(16 \%)\end{array}$ & $\begin{array}{c}\text { Not frail } \\
n=70(84 \%)\end{array}$ & $p$ \\
\hline $\begin{array}{l}\text { Age (y) } \\
\text { Mean (SD) }\end{array}$ & $61.3(7.9)$ & $39.8(16.6)$ & \\
$\begin{array}{l}\text { Median } \\
\text { (minimum, } \\
\text { maximum) }\end{array}$ & $60(50,76)$ & $36.5(18,87)$ & \\
$\begin{array}{l}\text { Gender } \\
\text { Female }\end{array}$ & $6(46 \%)$ & $23(33 \%)$ & 0.54 \\
Male & $7(54 \%)$ & $47(67 \%)$ & \\
Race & & \\
Black or African & $6(46 \%)$ & $42(60 \%)$ & \\
American & $7(54 \%)$ & $24(34 \%)$ & \\
Other & $0(0 \%)$ & $4(6 \%)$ & \\
Unknown & & \\
\hline
\end{tabular}

\section{Radiographical markers of frailty}

Frail patients had radiographical evidence of myosteatosis, and a lower average psoas $\mathrm{HU}(54.9 \pm 5.6)$ when compared with non-frail patients ( $64.5 \pm 7.6, p<0.001$; Table 8$)$. Furthermore, frail patients had radiographical evidence of L1 attenuation, and a lower average superior $\mathrm{HU}(158.1 \pm 28.7)$ when compared with non-frail $(225.7 \pm 73 \mathrm{HU})$ patients $(p<0.001$; Table 8$)$. In the contrast CT only subgroup analysis (Table 9 ), the average $\mathrm{HU}$ of the psoas muscle and superior HU of the L1 vertebra were significantly different between frail and non-frail patients $(p<0.0001)$. Multivariate regression (Table 10) analysis showed myosteatosis (average $\mathrm{HU}$ ) was predictive of an $\mathrm{mFI}-5$ score greater than or equal to $0.3(p<0.05)$.

Comparing patients who did or did not have an inhospital complication, there was no difference observed for myosteatosis, sarcopenia, or L1 attenuation. Similarly, radiographical markers of frailty were not associated with discharge disposition (home or care).
Table 8. Relationship between radiographic markers and frailty status (mFI Index $\geq 0.3$ ).

\begin{tabular}{lccc}
\hline & $\begin{array}{c}\text { Frail } \\
n=13(16 \%)\end{array}$ & $\begin{array}{c}\text { Not frail } \\
n=70(84 \%)\end{array}$ & $p$ \\
\hline Average HU & & & $<0.001$ \\
Mean (SD) & $54.9(5.6)$ & $64.5(7.6)$ & \\
$\begin{array}{l}\text { Mean (minimum, } \\
\text { maximum) }\end{array}$ & 54.4 & 63.5 & \\
Average SA & $(42.8,63.6)$ & $(42.5,87.6)$ & \\
Mean (SD) & & & 0.51 \\
Mean (minimum, & $32.5(30.8)$ & $26.4(7.1)$ & \\
maximum) & 22.3 & 25.6 & \\
Superior HU & $(19.4,129.6)$ & $(14.6,6.1)$ & \\
Mean (SD) & & & \\
Mean (minimum, & $158.1(28.7)$ & $225.7(73)$ & \\
maximum) & 163.8 & 224.8 & \\
\hline
\end{tabular}

$\mathrm{SA}=$ surface area

Table 9. Contrast CT analysis relationship between radiographic markers and frailty status ( $\mathrm{mFI}$ Index $\geq 0.3$ ).

\begin{tabular}{lccc}
\hline & $\begin{array}{c}\text { Frail } \\
n=9(12 \%)\end{array}$ & $\begin{array}{c}\text { Not frail } \\
n=65(88 \%)\end{array}$ & $p$ \\
\hline Average HU & & & 0.001 \\
Mean (SD) & $55.4(6.4)$ & $65.2(7.1)$ & \\
Mean (minimum, & 54.5 & 64.6 & \\
maximum) & $(42.8,63.6)$ & $(52.6,87.6)$ & \\
Average SA & & & 0.17 \\
Mean (SD) & $24.3(3.8)$ & $26.6(7.3)$ & \\
Mean (minimum, & 22.4 & 25.6 & \\
maximum) & $(19.7,31.6)$ & $(14.6,61)$ & \\
Superior HU & & & \\
Mean (SD) & $148.9(26.7)$ & $230.4(71)$ & \\
Mean (minimum, & 157.5 & 228.2 & \\
maximum) & $(104.1,177)$ & $(80.9,392.1)$ & \\
\hline
\end{tabular}

$\mathrm{CT}=$ computed tomography; $\mathrm{HU}=$ Hounsfield Units; $\mathrm{SA}=$ surface area.

Table 10. Multivariate logistic regression predicting the impact of radiographic markers on frailty, disposition, and complications.

\begin{tabular}{lccccccccc} 
& \multicolumn{3}{c}{ Sarcopenia (average SA) } & \multicolumn{3}{c}{ Myosteatosis (average HU) } & \multicolumn{3}{c}{ L1 attenuation (superior HU) } \\
\cline { 2 - 9 } & OR $[95 \% \mathrm{CI}]$ & ROC & $p$ & OR [95\% CI] & ROC & $p$ & OR [95\% CI] & ROC & $p$ \\
\hline mFI-5 $(\geq 3.0)$ & $0.924[0.754,1.076]$ & 0.908 & 0.386 & $0.781[0.619,0.924]$ & 0.928 & $<0.05$ & $0.991[0.968,1.01]$ & 0.897 & 0.423 \\
$\begin{array}{l}\text { Discharge } \\
\text { (home, care) }\end{array}$ & $0.994[0.908,1.072]$ & 0.608 & 0.882 & $1.032[0.958,1.111]$ & 0.604 & 0.4 & $0.999[0.988,1.009]$ & 0.619 & 0.801 \\
$\begin{array}{l}\text { Complications } \\
\text { (yes, no) }\end{array}$ & $1.031[0.93,1.124]$ & 0.667 & 0.498 & $1.039[0.933,1.146]$ & 0.625 & 0.452 & $1.012[1,1.026]$ & 0.737 & 0.057 \\
\hline
\end{tabular}

$\mathrm{CI}=$ confidence interval; $\mathrm{HU}=$ Hounsfield units $; \mathrm{mFI}-5$ = modified 5-item frailty index $; \mathrm{OR}=$ odd ratio ; ROC = receiver operating characteristic. 


\section{Discussion}

Morbidity and mortality in the United States due to trauma-related injuries accounts for nearly 150,000 deaths per year, coupled with over 100 billion dollars of healthcare expenditure [4]. Medical frailty is a well-known contributor to poor outcome following trauma [4]. Currently, several mFIs have been used for trauma and non-trauma patients to predict frailty, including the $\mathrm{mFI}-5, \mathrm{mFI}-11$, and $\mathrm{mFI}-15$ [6$8,10,11]$. While these have been shown to predict mortality and complications, they are often unable to be administered in an obtunded trauma patient. Radiographical markers, including psoas fatty atrophy, sarcopenia, and L1 attenuation have been proposed as surrogate markers of frailty [16,20-22]. These markers show potential for widespread use in trauma patients, where the CT CAP scan is often obtained at admission to hospitalization and triage. Prior to this study, there has been limited available evidence describing the relationship between radiographical markers of frailty, widely utilized trauma indices, and complications in trauma patients. The results of this study show that frailty, as measured by the $\mathrm{mFI}$, was associated with radiographical markers on the CT CAP, including psoas myosteatosis and L1 attenuation.

The role of assessing frailty in the trauma setting is pressing, as it necessitates speed, simplicity, and ease of implementation in obtunded patients. In the geriatric population, the use of frailty markers in the course of treatment in trauma patients is well recognized [36]. However, the incorporation of validated frailty indices is limited by lack of training, insufficient time, and the perceived burden of using assessment tools [36]. In the last few years, several studies have demonstrated the capacity of frailty scores and markers to predict postoperative outcomes [37,38]. Frailty and malnourishment have demonstrated a synergistic effect when compared with malnourishment alone in predicting the potential for postoperative complications [38]. Frailty has also been shown to increase the risk of postoperative morbidity, even when controlling for other comorbidities, and demographic factors [37]. Additionally, the mFI has shown capacity to significantly predict morbidity and mortality in young orthopedic trauma patients [4]. Hypoalbuminemia, a marker of frailty, has also been demonstrated to have a powerful capacity to predict mortality and the postoperative course, following surgical fixation in nongeriatric lower extremity orthopedic trauma patients.

The relationship between radiographical markers and frailty is a recent focus of study in the trauma setting. Research on sarcopenia and myosteatosis has demonstrated an association with complications in surgical and cancer patient populations [27-32,39]. The presence of frailty is shown to be associated with mortality, adverse outcomes from discharge, and multisystem trauma complications [40]. Composite scores for radiographical markers for frailty including sarcopenia, and sarcopenic obesity are reported to predict a poor outcome from discharge from hospital [41]. Sarcopenia, along with other radiographical markers, have significantly demonstrated severe thoracic injury in the trauma setting [42]. With specific regards to orthopedic trauma, the simple radiographical marker Chinon-Chest in Neck of Femur may be used to identify patients with increased frailty and risk of mortality following traumatic hip fractures [43]. This current study expands on prior findings and introduces a novel radiographical maker to the dialogue of identification of frailty by expanding the current understanding of how the radiographical marker L1 vertebra attenuation is related to frailty. Current literature highlights its relationship with aging and osteoporosis [22], but the relationship with frailty indices has not been well-defined [33-35].

This study is a prospective cohort of orthopedic, and general trauma patients and includes an assessment of the mFI-5 and multiple radiographical markers (including sarcopenia, myosteatosis, and L1 attenuation) in the same patient. Previous studies have been limited because they have often studied separate populations $[30,31,44-46]$. Furthermore, the addition of the L1 attenuation is novel to the diagnostic algorithm in trauma patients. Moreover, the role of contrast in the CAP CT scans was incorporated because this is a key component to density measurements [47]. The primary weakness of the study was that the study was not powered to assess the associations with complications, mortality, and hospital utilization. Future, large, prospective series will need to incorporate the frailty indices, and radiographical measurements to assess the predictive validity of these outcomes.

In conclusion, radiographical markers of frailty (myosteatosis and L1 attenuation) in this study were associated with frailty as measured by the mFI- 5 in trauma patients. This allows a quick, comprehensive assessment using data already obtained during the trauma work-up, and facilitates early interdisciplinary coordination of care for trauma patients.

\section{Conflicts of Interest}

The authors have no conflicts of interest to declare.

\section{Ethical Statement}

The study was a prospective cohort with informed consent and the IRB number is IRB00086957. 


\section{References}

[1] Cooper Z, Rogers Jr SO, Ngo L, Guess J, Schmitt E, Jones RN, Ayres DK, et al. Comparison of Frailty Measures as Predictors of Outcomes After Orthopedic Surgery. J Am Geriatr Soc 2016;64(12):2464-71.

[2] Rebagliati GAA, Sciumè L, Iannello $P$, Mottini A, Antonietti A, Caserta VA, et al. Frailty and resilience in an older population. The role of resilience during rehabilitation after orthopedic surgery in geriatric patients with multiple comorbidities. Funct Neurol 2016;31(3):171-7.

[3] Sun X, Shen Y, Yang J, Qiu L, Ji M, Shen J. Frailty is an independent predictor of postoperative complications after elective orthopedic surgery: A prospective cohort study. J Clin Anesth 2020;63:109691.

[4] Rege RM, Runner RP, Staley CA, Vu CCL, Arora SS, Schenker ML. Frailty predicts mortality and complications in chronologically young patients with traumatic orthopaedic injuries. Injury 2018;49(12):2234-8.

[5] Al-Khamis A, Warner C, Park J, Marecik S, Davis N, Mellgren A, et al. Modified frailty index predicts early outcomes after colorectal surgery: an ACS-NSQIP study. Colorectal Dis 2019;21(10):1192-205.

[6] Traven SA, Horn RW, Reeves RA, Walton ZJ, Woolf SK, Slone HS. The 5-Factor Modified Frailty Index Predicts Complications, Hospital Admission, and Mortality Following Arthroscopic Rotator Cuff Repair. Arthroscopy 2020;36(2):383-8.

[7] Traven SA, McGurk KM, Reeves RA, Walton ZJ, Woolf SK, Slone HS. Modified frailty index predicts medical complications, length of stay, readmission, and mortality following total shoulder arthroplasty. J Shoulder Elbow Surg 2019:28(10):1854-60.

[8] Traven SA, Reeves RA, Althoff AD, Slone HS, Waltong ZJ. New Five-Factor Modified Frailty Index Predicts Morbidity and Mortality in Geriatric Hip Fractures. J Orthop Trauma 2019;33(7):319-23.

[9] Traven SA, Reeves RA, Sekar MG, Slone HS, Walton ZJ. New 5-Factor Modified Frailty Index Predicts Morbidity and Mortality in Primary Hip and Knee Arthroplasty. J Arthroplasty 2019;34(1):140-4.

[10] Yagi M, Michikawa T, Hosogane N, Fujita N, Okada E, Suzuki S, et al. The 5-Item Modified Frailty Index Is Predictive of Severe Adverse Events in Patients Undergoing Surgery for Adult Spinal Deformity. Spine (Phila Pa 1976) 2019;44(18):E1083-91.

[11] Ali TZ, Lehman EB, Aziz F. Modified Frailty Index Can Be Used to Predict Adverse Outcomes and Mortality after Lower Extremity Bypass Surgery. Ann Vasc Surg 2018;46:168-77.

[12] Madbouly K, AlHajeri D, Habous M, Binsaleh S. Association of the modified frailty index with adverse outcomes after penile prosthesis implantation. Aging Male 2017;20(2):119-24.

[13] Joseph B, Pandit V, Zangbar B, Kulvatunyou N, Tang A, O'Keeffe T, et al. Validating trauma-specific frailty index for geriatric trauma patients: a prospective analysis. J Am Coll Surg 2014;219(1):10-17.e1.

[14] Brohi K, Healy M, Fotheringham T, Chan O, Aylwin C, Whitley S, et al. Helical computed tomographic scanning for the evaluation of the cervical spine in the unconscious, intubated trauma patient. J Trauma 2005;58(5):897-901.

[15] Hubbard RE, Story DA. Patient frailty: the elephant in the operating room. Anaesthesia 2014;69 Suppl 1:26-34.

[16] Balsam LB. Psoas muscle area: a new standard for frailty assessment in cardiac surgery? J Thorac Dis 2018;10(Suppl 33):S3846-9.

[17] Chiang PL, Chen YS, Lin AW. Altered Body Composition of Psoas and Thigh Muscles in Relation to Frailty and Severity of Parkinson's Disease. Int J Environ Res Public Health 2019;16(19):3667.

[18] Kim HJ. You cannot assess until you measure it: using psoas index for measuring frailty. J Thorac Dis 2018;10(12):6412-3.

[19] Kleczynski P, Tokarek T, Dziewierz A, Sorysz D, Bagienski M, Rzeszutko L, et al, Usefulness of Psoas Muscle Area and Volume and Frailty Scoring to Predict Outcomes After Transcatheter Aortic Valve Implantation. Am J Cardiol 2018;122(1):135-40.

[20] Paknikar R, Friedman J, Cron D, Deeb GM, Chetcuti S, Grossman PM, et al. Psoas muscle size as a frailty measure for open and transcatheter aortic valve replacement. J Thorac Cardiovasc Surg 2016;151(3):745-51.

[21] Graffy PM, Lee SJ, Ziemlewicz TJ, Pickhardt PJ. Prevalence of Vertebral Compression Fractures on Routine CT Scans According to L1 Trabecular Attenuation: Determining Relevant Thresholds for Opportunistic Osteoporosis Screening. AJR Am J Roentgenol 2017;209(3):491-6.

[22] Jang S, Graffy PM, Ziemlewicz TJ, Lee SJ, Summers RM, Pickhardt PJ. Opportunistic Osteoporosis Screening at Routine Abdominal and Thoracic CT: Normative L1 Trabecular Attenuation Values in More than 20000 Adults. Radiology 2019;291(2):360-7.

[23] Bourassa-Moreau E, Versteeg A, Moskven E, Charest-Morin R, Flexman A, Ailon T, et al. Sarcopenia, but not frailty, predicts early mortality and adverse events after emergent surgery for metastatic disease of the spine. Spine J 2020;20(1):22-31.

[24] Nascimento CM, Ingles M, Salvador-Pascual A, Cominetti MR, GomezCabrera MC, Viña J. Sarcopenia, frailty and their prevention by exercise. Free Radic Biol Med 2019;132:42-9.

[25] Woo J. Combating frailty and sarcopenia in aging populations: Switching to a more positive paradigm. Aging Med (Milton) 2019;2(1):7-10.

[26] Souza NC, Gonzales MC, Martucci RB, Rodrigues VD, de Pinho NB, de Leon AP, et al. Frailty is associated with myosteatosis in obese patients with colorectal cancer. Clin Nutr 2020;39(2):484-91.

[27] Lee JS, He K, Harbaugh CM, Schaubel DE, Sonnenday CJ, Wang SC, et al. Frailty, core muscle size, and mortality in patients undergoing open abdominal aortic aneurysm repair. J Vasc Surg 2011;53(4):912-7.

[28] Lieffers JR, Bathe OF, Fassbender K, Winget M, Baracos VE. Sarcopenia is associated with postoperative infection and delayed recovery from colorectal cancer resection surgery. Br J Cancer 2012;107(6):931-6.

[29] Sheetz KH, Zhao L, Holcombe SA, Wang SC, Reddy RM, Lin J, et al. Decreased core muscle size is associated with worse patient survival following esophagectomy for cancer. Dis Esophagus 2013;26(7):716-22.

[30] Rier HN, Jager A, Sleijfer S, van Rosmalen J, Kock MCJM, Levin M. Low muscle attenuation is a prognostic factor for survival in metastatic breast cancer patients treated with first line palliative chemotherapy. Breast 2017;31:9-15.

[31] Hamaguchi Y, Kaido T, Okumura S, Kobayashi A, Fujimoto Y, Ogawa K, et al. Muscle Steatosis is an Independent Predictor of Postoperative Complications in Patients with Hepatocellular Carcinoma. World J Surg 2016;40(8):1959-68.

[32] Krishnan M, Beck S, Havelock W, Eeles E, Hubbard RE, Johansen A. Predicting outcome after hip fracture: using a frailty index to integrate comprehensive geriatric assessment results. Age Ageing 2014;43(1):1226.

[33] Gajic-Veljanoski O, Papaioannou A, Kennedy C, Ioannidis G, Berger C, Wong AKO, et al. Osteoporotic fractures and obesity affect frailty progression: a longitudinal analysis of the Canadian multicentre osteoporosis study. BMC Geriatr 2018;18(1):4.

[34] Li G, Thabane L, Papaioannou A, Ioannidis G, Levine MAH, Adachi JD. An overview of osteoporosis and frailty in the elderly. BMC Musculoskelet Disord, 2017;18(1):46.

[35] Wang YJ, Wang Y, Zhan J, Tang Z, He J, Tan P, et al. Sarco-Osteoporosis: Prevalence and Association with Frailty in Chinese Community-Dwelling Older Adults. Int J Endocrinol 2015;2015:482940.

[36] Shoultz TH, Moore M, Reed MJ, Kaplan SJ, Bentov I, Hough C, et al. Trauma Providers' Perceptions of Frailty Assessment: A Mixed-Methods Analysis of Knowledge, Attitudes, and Beliefs. South Med J 2019;112(3):159-63.

[37] Amer KM, Congiusta DV, Suri P, Merchant AM, Vosbikian MM, Ahmed IH, et al. Patient frailty as a risk assessment tool in surgical management of long bone fractures. J Clin Orthop Trauma 2020;11(Suppl 4):S591-5.

[38] Phen HM, Jones C, Kravets VG, Farley KX, Schwartz AM, Wilson JM, et al. The Impact of Frailty and Malnutrition on Outcomes Following Surgical Fixation of Lower Extremity Fractures in Young Patients. J Orthop Trauma 2020;35(4):e126-33.

[39] Buettner S, Wagner D, Kim Y, Margonis GA, Makary MA, Wilson A, et al. Inclusion of Sarcopenia Outperforms the Modified Frailty Index in Predicting 1-Year Mortality among 1,326 Patients Undergoing Gastrointestinal Surgery for a Malignant Indication. J Am Coll Surg 2016;222(4):397-407.e2.

[40] Poulton A, Shaw JF, Nguyen F, Wong C, Lampron J, Tran A, et al. The Association of Frailty With Adverse Outcomes After Multisystem Trauma: A Systematic Review and Meta-analysis. Anesth Analg 2020;130(6):148292.

[41] Lauerman MH, Raithel M, Kufera J, Shanmuganathan K, Bruns BR, Scalea $\mathrm{TM}$, et al. Comparison of individual and composite radiographic markers of frailty in trauma. Injury 2019;50(1):149-55.

[42] Oskutis MQ, Lauerman MH, Kufera JA, Shanmuganathan K, Burch C, Kerns $\mathrm{T}$, et al. Are frailty markers associated with serious thoracic and spinal injuries among motor vehicle crash occupants? J Trauma Acute Care Surg 2016;81(1):156-61.

[43] Egglestone A, Dietz-Collin G, Eardley W, Baker P. Chin-on-Chest in Neck of Femur Fracture (COCNOF) sign: A simple radiographic predictor of frailty and mortality in hip fracture patients. Injury 2020;52(6):1494-9.

[44] Kaplan SJ, Pham TN, Arbabi S, Gross JA, Damodarasamy M, Bentov I, et al. Association of Radiologic Indicators of Frailty With 1-Year Mortality in Older Trauma Patients: Opportunistic Screening for Sarcopenia and Osteopenia. JAMA Surg 2017;152(2):e164604.

[45] Kumar A, Moynagh MR, Multinu F, Cliby WA, McGree ME, Weaver $\mathrm{AL}$, et al. Muscle composition measured by CT scan is a measurable 
predictor of overall survival in advanced ovarian cancer. Gynecol Oncol 2016;142(2):311-6.

[46] Rogers MA, Evans WJ. Changes in skeletal muscle with aging: effects of exercise training. Exerc Sport Sci Rev 1993;21:65-102.
[47] Boutin RD, Kaptuch JM, Bateni CP, Chalfant JS, Yao L. Influence of IV Contrast Administration on CT Measures of Muscle and Bone Attenuation: Implications for Sarcopenia and Osteoporosis Evaluation. AJR Am J Roentgenol 2016;207(5):1046-54. 